Artigo original

Hegemonia - Revista Eletrônica do Programa de Mestrado em Direitos Humanos, Cidadania e Violência/Ciência Política do Centro Universitário Unieuro

ISSN: 1809-1261

UNIEURO, Brasília, número 29, Janeiro a Junho de 2020, pp. 154-176.

Recebido em: 24/8/2019

Avaliado em: 28/9/2019

Aprovado em: 18/10/2019

\title{
LA RECONSTITUCIÓN DE LA POLÍTICA POR LA REVOLUCIÓN CIUDADANA EN EL ECUADOR: HEGEMONÍA, DISCURSO Y POLÍTICA INTERNACIONAL PREVIOS A LA TOMA DEL PODER
}

Werner Vásquez von Schoettler ${ }^{1}$ y Alessandro Rezende da Silva ${ }^{2}$

Resumo: O presente artigo analisa os momentos discursivos da Revolução Cidadã, na configuração anti hegemônica e, consequentemente, a uma hegemonia cidadã popular. As marcas significativas para a disputa política e sua posterior reconfiguração do Estado e a Sociedade. Finalmente quais foram os anúncios e contribuições para uma nova política exterior, relações internacionais no contexto da integração regional. A metodologia utilizada utiliza uma retórica histórica, analítica descritiva na análise do discurso. Os resultados obtidos evidenciam que as matrizes discursivas foram produzidas pelos cidadãos e referenciadas no discurso presidencial como narrativa hegemónica.

Palabras claves: Hegemonia; discurso, política internacional, significante vazio, neoliberalismo.

Resumen: El presente artículo analiza los momentos discursivos de la llamada Revolución Ciudadana, en la configuración contra hegemónica y su paso a una hegemonía de tipo ciudadana-popular. Las consignas significativas para la disputa política y la posterior reconfiguración del Estado y la sociedad. Y, finalmente, cuáles fueron los enunciados y postulados para una nueva política exterior, relaciones internacionales, en el contexto de la integración regional. La metodología utilizada es de tipo histórica, analítica descriptiva y del análisis del discurso. Los resultados obtenidos evidencian que las matrices discursivas fueron producidas desde los ciudadanos y nucleadas en el discurso presidencial como narrativa hegemónica.

Palabras claves: Hegemonía; discurso, política internacional, significante vacío, neoliberalismo.

Abstract: The present article analyses the discursive moments of the called Citizen Revolution, in the anti-hegemonic configuration and its transformation into a popular citizen hegemony. The meaningful slogan for the political dispute and the next reconfiguration of the State and the society are also analyzed. Finally, it is examined which the statements and postulates for a new foreign policy were, international relations, in the

\footnotetext{
${ }^{1}$ Doutor em Ciências Sociais e docente da Facultade Latino-americana de Ciências Sociais Sede Equador.

${ }^{2}$ Doutor em Ciências Sociais e docente do Instituto Superior de Ciências Policiais (Brasília).
} 
Artigo original

Hegemonia - Revista Eletrônica do Programa de Mestrado em Direitos Humanos, Cidadania e Violência/Ciência Política do Centro Universitário Unieuro

ISSN: 1809-1261

UNIEURO, Brasília, número 29, Janeiro a Junho de 2020, pp. 154-176.

regional integration context. The methodology used is historic, descriptive analytic and discourse analysis. The gotten results evidence that the discursive matrices were produced by the citizens and they were the core of the presidential speech as hegemonic narrative.

Keywords: Hegemony; discourse, international politics, empty signifier, neoliberalism.

\section{Introducción}

El presente artículo tiene como propósito exponer analíticamente la configuración contra hegemónica producida en el Ecuador antes del año 2007. Cómo se fue construyendo una nueva hegemonía ciudadana-popular desde un discurso de una izquierda autodefinida como progresista, del siglo XXI, alfarista, bolivariana. Expuesto las categorías claves del nuevo discurso contra hegemónico-hegemónico se examina, el caso particular de la nueva política exterior, de las nuevas relaciones internacionales, de la política internacional del nuevo gobierno que asumiría el poder por una década.

Este caso de estudio de los momentos previos se inscribe en una investigación sobre la construcción del discurso presidencial, en la figura del presidente Rafael Correa como núcleo de irradiación ideológica-política que significó un cambio profunda tanto en las relaciones de poder, los escenarios, los actores, como el rol del Estado, de la economía y el lugar de la ciudadanía, siempre en el contexto de que dichos cambios fueron articulados en un plan de gobierno, pero sobre todo en la formulación de una nueva Constitución aprobada en referéndum en el 2008 y que aún sigue vigente.

Por eso es de relevancia comprender la caracterización que tuvo este proceso en sus momentos previos desde la década de los noventa y el primer lustro del Siglo XXI.

\section{Metodología}

La metodología utilizada es de tipo histórica, se ha utilizado categorizaciones de la sociología política como del análisis del discurso. El análisis principalmente es de tipo analíticodescriptivo sobre los momentos previos al triunfo electoral de Alianza PAIS en el 2006 y la toma de poder en el 2007 (Dalle, Boniolo, Sautu, Elbert, 2005; Van Dijk, 1999). 
Artigo original

Hegemonia - Revista Eletrônica do Programa de Mestrado em Direitos Humanos, Cidadania e Violência/Ciência Política do Centro Universitário Unieuro

ISSN: 1809-1261

UNIEURO, Brasília, número 29, Janeiro a Junho de 2020, pp. 154-176.

3. El Ecuador de la partidocracia: un breve recorrido histórico

Las ciencias sociales y humanas en el Ecuador de manera permanente han buscado situar las causas y causalidades de las contradicciones de la política nacional. Sea desde una perspectiva histórica fundacional del Estado y la Nación republicana desde 1830 o desde una perspectiva nacionalista con la Revolución Alfarista de 1895 (Ayala Mora, 2008) o desde perspectivas economicistas sobre la estructura productiva, comercial, financiera del país sujeta a determinados productos dependientes en sus precios al mercado internacional. Incluso cuando estas explicaciones no han bastado para explicar la complejidad del entramado político, se ha recurrido a rastrear los "males de la patria" en el paso de un Estado Colonial altamente opresor, centrado en un sistema hacendatario de explotación y expoliación de las poblaciones étnicas y la hiperconcentración de la riqueza por parte de élites regionales centradas en tributar menos a la Corona Española, tener mayor autonomía, independencia pero sin cambiar las relaciones de poder al interior de los territorios coloniales.

La propia gesta libertaria de inicios del siglo XIX fue contradictoria entre sus protagonistas: no hubo una agenda, por decirlo así, de tipo nacional o nacionalista. Las mentalidades regionales, la centralidad de Quito como el lugar de la política y la pérdida de su centralidad económica que se desplazó rápidamente a la costa ecuatoriana, principalmente al "puerto principal" Guayaquil, descentró más aún la posibilidad de pensar y hacer una política desde una representación de lo nacional. A esto hay que sumarle que la propia geografía del territorio sirvió de marcadores territoriales locales para la administración y constitución de poderes locales (Acosta, 2001). Es decir, que la geografía natural del territorio, sirvió de base para una geo-política territorial con fuerte fragmentación, donde, las viejas instituciones como la Iglesia Católica y sus modos de ordenamiento territorial continuaron bajo la naciente república y que se conservan hasta estos días, por ejemplo, los municipios, las juntas parroquiales. Las provincias, como concepto organizador del territorio políticamente, se constituyó en el pilar de la administración jurídica-política de las localidades. Desde la idea de provincia se forjaron relaciones de administración de poblaciones en la llamada "Sierra", eje que gradualmente a medida que la república se organizaba, fue desplazada por el nuevo eje exportador de la "Costa".

A lo largo del siglo XIX, lo que actualmente se conoce como Amazonía, no estaba incorporada al imaginario de la Nación. Simplemente eran territorios "salvajes", solo con la 
Artigo original

Hegemonia - Revista Eletrônica do Programa de Mestrado em Direitos Humanos, Cidadania e Violência/Ciência Política do Centro Universitário Unieuro

ISSN: 1809-1261

UNIEURO, Brasília, número 29, Janeiro a Junho de 2020, pp. 154-176.

proyección de que en esos territorios existirían ingentes recursos petroleros, es que esos territorios se incorporaron al imaginario de la Nación como el "oriente ecuatoriano".

Categorización que permitiría una comprensión geográfica como recurso potencial de ingentes riquezas. Mientras tanto la "Sierra" y la "Costa" a fines del siglo XIX ya se convertían en rivales, la idea política de la "región", del "regionalismo" fue brotando como la expresión efectiva de enfrentar al viejo régimen centrado en el imaginario en la capital, Quito, versus, las fuerzas emergentes modernizadoras de la "Costa", representadas por los grandes productores y exportadores, mucho más vinculados a los centros metropolitanos de Europa y Estados Unidos, que Quito, la cual parecía inamovible bajo la poderosa administración ideológica de la Iglesia Católica y su proyecto de una Modernidad Católica (Buriano, 2014; Perla, 2015) nacional para el Ecuador.

Estas poderosas contradicciones entre regiones, implicaban fuerzas económicas y financieras enfrentadas, incluso teniendo como alternativa la separación territorial y la formación de dos países. Es ahí cuando el proceso de la Revolución Liberal de 1895, rompe con ese pacto de las élites regionales y su estatus quo o la formación de dos países.

Esta Revolución fue el primer intento de modernización liberal de conformación de estructuras estatales nacionales, de conformar un Estado Nacional, de constituir unas Fuerzas Armadas nacionalistas, las cuales después y hasta el día de hoy junto a la Iglesia Católica son reconocidas como las instituciones de mayor credibilidad para la ciudadanía.

En el medio y como actores centrales de estos intentos modernizadores, se transformaron las viejas fuerzas conservadoras y liberales. Para las primeras décadas del siglo XX, surge nuevos partidos, sobre todo el Comunista y el Socialista (Becker, 2006; Rodas, 2000), que entran a disputar a las viejas fuerzas políticas. Estas nuevas fuerzas incorporarán una nueva visión sobre lo que es un "partido" organizado y orgánico, con el objetivo de tomarse el poder a través de una nueva revolución.

Paradójicamente, los cambios más innovadores en la primera mitad del siglo XX, no vendrían de estas fuerzas, sino, nuevamente de una revolución protagonizada por oficiales jóvenes de las Fuerzas Armadas: la Revolución Juliana de 1925 (Paz y Miño, 2013) se convertiría el intento más avanzado de afianzar la Revolución Alfarista de 1895, de constituir instituciones claves, como el Banco Central del Ecuador, la Contraloría General del Estado, entre otras. Lo clave en este punto fue que tuvieron la capacidad de consolidar a las Fuerzas Armadas como la tercera fuerza, como el agente político mediador y de resolución de las crisis de los 
Artigo original

Hegemonia - Revista Eletrônica do Programa de Mestrado em Direitos Humanos, Cidadania e Violência/Ciência Política do Centro Universitário Unieuro

ISSN: 1809-1261

UNIEURO, Brasília, número 29, Janeiro a Junho de 2020, pp. 154-176.

partidos políticos y de sus élites. Este hecho marcaría la política nacional de todas las futuras décadas en el Ecuador. Nuevamente de forma paradójica y a diferencia del lugar común de las otras Fuerzas Armadas en América Latina, las ecuatorianas (Saltos, 2017) se forjaron desde una perspectiva nacional-popular, incluso para la última dictadura de 1972, se llegan a formularse como una fuerza nacional-revolucionaria.

Este breve, pero necesario panorama de fuerzas en el Ecuador es vital a la hora de buscar comprender no solo las fuerzas políticas partidarias, sino la lógica de las fuerzas sociales, la lógica del Estado Nacional fragmentario. Los pactos y acuerdos regionales y la emergencia de lo popular; la relevancia de aquello llamado "democracia", y que desde el llamado "retorno a la democracia” en 1979, le significó al Ecuador varias décadas de profunda inestabilidad económica, social, política que tendría en 1999, su punto más álgido cuando el Ecuador cayó en la más grave y profunda crisis económica y social de su historia, que terminaría en la dolarización de la economía, junto a la expulsión de cerca de un millón y medio de ecuatorianos (Ramiréz, 2005; Tomalá, 2016) a distintos países de Europa, principalmente a España e Italia, y hacia los Estados Unidos de América.

La democracia un significante vaciado

El Latinobarómetro de 2007, evidenciaba en su encuesta para 18 países de la región que el Ecuador ocupaba el último lugar en confianza a la clase gobernante. Y que solo uno de cada diez ciudadanos se manifestaba satisfecho con la democracia, mientras que, para el resto de América Latina, eran cuatro de diez. Además, que uno de cada diez ecuatorianos creía que sus gobernantes trabajaban para el bien común. Evidentemente esto expresaba una profunda insatisfacción, una profunda desconfianza en la "clase política". El ecuatoriano promedio consideraba que los distintos gobiernos, los distintos gobernantes, los políticos casi en su totalidad no trabajaban para el "bien común", sino que privilegiaban los intereses de las élites regionales-nacionales. Es significaba además que la población en su mayoría se observaba a sí misma como una víctima de los grupos de poder, una víctima de un sistema político corrompido; víctima de un sistema de partidos políticos locales, regionales y nacionales totalmente corruptos. Entonces la asociación de democracia y partidos políticos era íntima (Muñoz, 2006; Larrea, s/f; Paltán, 2005; Oleas, 2017). 
Artigo original

Hegemonia - Revista Eletrônica do Programa de Mestrado em Direitos Humanos, Cidadania e Violência/Ciência Política do Centro Universitário Unieuro

ISSN: 1809-1261

UNIEURO, Brasília, número 29, Janeiro a Junho de 2020, pp. 154-176.

En consecuencia la valoración sobre la democracia era negativa o en general irrelevante para las mayorías, ya que la misma aparecía como un privilegio de los grupos tradicionales, no solo de las élites, sino de la clase política propietaria de un sistema de partidos políticos que reciclaba a sus dirigentes cada cierto tiempo; que se turnaban los distintos puestos en las funciones, en los llamados "poderes del Estado", con lo cual la política terminó por expresar y representar los antivalores de lo nacional-popular.

La democracia, terminó por ser representada como un antivalor a lo popular, entendiéndose no solo lo popular a las clases populares, sino a la propia clase media tradicional. Un antivalor que terminaba sistemáticamente depredando las opciones sociales de movilidad social. Las opciones de reconocimiento legítimo en términos de Honneth (1997, 2006), es decir, de autoreconocimiento desde las relaciones intersubjetivas materiales, simbólicas-afectivas, fueron primando frente a las formas y modos de reconocimiento ideológico que partían desde el Estado de las élites, que finalmente reconocieron al Ecuador como un país pluricultural, una de las demandas mayores del Movimiento Indígena Ecuatoriano (MIE), que fue recogida en la Constitución de 1999, pero que en la práctica del Estado, significaron una total indiferencia hacia la diversidad étnica en el país.

Ese reconocimiento ideológico rápidamente se desveló como vacío, eminentemente hiperjuridizado, sin materialización objetiva en el mejoramiento de los grupos históricamente excluidos, por el contrario, ese reconocimiento de tipo ideológico terminó por desarmar al propio MIE, el cual, sin duda, se había convertido en la década de los noventa en el acumulador de las fuerzas sociales, al presentar un proyecto político interétnico-nacional para el Ecuador. Sin embargo, hay que tener presente que a medida que ese reconocimiento ideológico, generaba un sinnúmero de formas de "agravio moral" (Honneth, 2010) en la ciudadanía, esta respondía con formas “espontáneas" de organización, como fueron las Asambleas Ciudadanas, las cuales se fueron organizando en barrios, en universidades, en distintas ciudades, con el objetivo de organizarse para desbancar a la clase política y "hacer presencia", de enfrentarse contra el régimen de turno y manifestar un "que se vayan todos" todos los políticos, incluso estas Asambleas proponían que los militares, nuevamente intervengan a favor de la ciudadanía. Intervengan para "salvar la Patria".

Lo que evidenciamos es que a fines de los noventa y los primeros años de dolarización forzada a la que fue sometida no solo la economía, sino todos los ciudadanos, estaba terminada, vaciada de significados positivos en los cuales la ciudadanía pudiese sentirse 
Artigo original

Hegemonia - Revista Eletrônica do Programa de Mestrado em Direitos Humanos, Cidadania e Violência/Ciência Política do Centro Universitário Unieuro

ISSN: 1809-1261

UNIEURO, Brasília, número 29, Janeiro a Junho de 2020, pp. 154-176.

representada. Las ubicaciones y posiciones (Laclau, 1978, 1987, 2005) de la democracia como significante se encontraban en las antípodas de los valores mayoritarios, entonces, cuando se hablaba de democracias, lo que se entendía o mejor dicho se valoraba era una serie de discursos ajenos a la voluntad popular, a la voluntad de las mayorías.

El sentimiento generalizado era que la voluntad ciudadana era violentado sistemáticamente.

Primero se pasó a una fase de indiferencia generalizada, expresada en el común decir: "soy independiente", "no soy político", a una fase en que "el que se vayan todos", significaba retomar o que retome la política, pero desde lo ciudadano.

La categoría de "ciudadanos" fue clave como el nuevos significantes dinámico que podía con fuerza recoger la diversidad de voces, sentires, pensares, y lugares de la diferencia para enfrentar a las élites tradicionales y al Estado. Ese nuevo significado de ese significante que no había habitual en los discursos políticos, se convirtió en el vehículo significantes para la representación común, de los "comunes". Hablar de "pueblo" no era suficiente, porque este concepto estuvo, casi siempre asociados a los discursos de la izquierda que se la catalogaría como "tradicional", aquella izquierda que en sus discursos decía ser la antípoda de las élites tradicionales, luchar por las mayorías desposeídas, pero que en la práctica, por lo menos desde el llamado "retorno a la democracia" en 1979, hizo un pacto de hecho, precisamente, con sus "enemigos históricos", entonces, la consecuencia fue la que todos esas organizaciones política, esos actores de derecha e izquierda, "tenían que irse para su casa" y era necesario que se de paso a nuevas figuras políticas no cooptadas por esas fuerza tradicionales.

Fue a estas fuerzas tradicionales a las que se catalogaría como la "partidocracia", incluidos los sindicatos, que de igual manera solo habían representado los intereses de sus miembros, pero con una nula capacidad de recoger demandas más allá de las propias, lo que les costaría, hasta el día de hoy, una profunda democracia de su rol en sociedad. En este sentido podemos decir que lo que sucedía en las décadas post dictadura en el Ecuador era una situación de hegemonía asimétrica (Gramsci, 1984, 1999), es decir, que el campo político esta delimitado, marcado por una lógica exponencial del conflicto y la contingencia, donde las parte en disputas (Ranciere, 2006), se partían, se fragmentaban sistemáticamente y que a pesar de las reacciones de rechazo, las mismas alimentaban el imaginario y la práctica política de que el valor de la democracia se centraba casi únicamente en el ejercicio electoral: "ir a votar" y nada más. Un reduccionismo que, por un lado, satisfacía a la élites políticas como a sus 
Artigo original

Hegemonia - Revista Eletrônica do Programa de Mestrado em Direitos Humanos, Cidadania e Violência/Ciência Política do Centro Universitário Unieuro

ISSN: 1809-1261

UNIEURO, Brasília, número 29, Janeiro a Junho de 2020, pp. 154-176.

enemigos políticos, logrando la legalidad necesaria y, por el otro lado, una legitimidad construida desde los aparatos mediáticos que consagraban una agenda informativa, finamente elaborada (MCCombs, 2004) donde el rechazo colectivo terminaba constituyéndose en una "fiesta democrática" de participación de los electores; donde el voto nulo o las bajas participaciones eran posicionadas como resultado de los actores políticos populistas.

De esta manera la acción hegemónica, era un hecho de sucesiones políticas formales, institucionalizadas y avaladas por las instituciones estatales, que otorgaban reconocimiento ideológico desde el Estado a la sociedad de electores; una forma de igualación social de las responsabilidades frente a quienes eran electos. Finalmente, los “desencantados" de la política, no se posicionaban, ni a favor, ni en contra, simplemente desde una posición pasiva, asumían la política como un caos permanente, casi insoluble, y que algún momento "tocaríamos fondo". Pero, sin duda, que este estado de situación, fue un estado de “dominación” de facto, podemos decir que, incluso, por la conflictividad social, por la confusión generalizada y el rechazo contenido en la ciudadanía, había un ejercicio activo de liderazgo rotativo entre los grupos dominantes.

La propia izquierda marxista, leninista, maoísta y todas sus fragmentaciones, estaban plenamente involucradas en este ejercicio de hegemonía, plenamente dominante. Pensar a esa fuerza como tal, es decir, con capacidad de movilización y acción frente a su enemigo histórico Estado/élites, no resultaba posible, porque habían coexistido con ellas, entonces, no tenían la capacidad de significar lo que estaba pasando.

Pensar en "huelgas de masas, partido y sindicatos" (Luxemburgo, 1975) tampoco era posible; el vaciamiento de participación, de acción colectiva "orgánica” mediante estos mecanismos, no encontraban su alter significativo en las fuerzas populares. Entonces pensar en una situación de "articulación" de las fuerzas populares, era posible, pero, siempre y cuando las propias fuerzas "históricas" de izquierda se quedaran al margen.

El carácter de clase se volvía difuso, y gradualmente la "disputa" se situaba entre lo ciudadano y todas las "fuerzas de la partidocracia", donde no era posible, diálogo alguno, porque los discursos de los "políticos" terminaban por corromper las "legítimas aspiraciones de la ciudadanía". Fue de este modo que el concepto "pueblo" por sí mismo, se saturó de significaciones que aludían a la vieja izquierda, como a la forma y usos que la derecha 
Artigo original

Hegemonia - Revista Eletrônica do Programa de Mestrado em Direitos Humanos, Cidadania e Violência/Ciência Política do Centro Universitário Unieuro

ISSN: 1809-1261

UNIEURO, Brasília, número 29, Janeiro a Junho de 2020, pp. 154-176.

populista, había dado a la misma, como la gran masa, amorfa, dispuesta a volatilizarse a medida de las demandas de sus líderes.

"Ciudadanía" fue el nuevo significante abarcador, lleno de significaciones de ruptura, de quiebre institucional. Ni siquiera la "huelga" era un dispositivo para la paralización, contra el enemigo político; los propios lugares de la disputa callejera, principalmente en Quito, como la "capital política del país", fueron cambiando, como sus actores. Actores tradicionales y sus lugares como fue el caso de los estudiantes universitarios, principalmente de la Universidad Central del Ecuador (UCE) la más antigua de las universidades del país, y los colegios públicos que cada semana salían a protestar, dejaron de ser el centro del activismo.

Lentamente nuevos sectores, nuevos lugares de la protesta se fueron gestando. Estudiantes de universidades privadas, empleados públicos, empleados privados, amplios sectores de clase media, entraron en un nuevo escenario de confrontación. Los tiempos de las movilizaciones cambiaron, ya no eran las confrontaciones alrededor del UCE, como epicentro de la acción callejera, sino nuevas calles y avenidas, nuevas rutas aparecieron, incluso, en sectores jamás pensando para manifestaciones de los miembros de los centenares de Asambleas Ciudadanas, gestadas en el rechazo a la "partidocracia".

El cambio de ejes de la disputa callejera, la participación del estudiantado de universidades privadas-religiosas fue un nuevo elemento que se sumaban al ejercicio de rechazar "todo lo instituido" y de ser solidarios con los que "habían luchado y habían sido traicionadas" como fue el caso de los indígenas y sus organizaciones, pero que ahora ya no lograban concentrar en el nuevo significante, una vOz unitaria y concentradora de fuerzas ética, sino que eran un actor importante, un referente por sus luchas en los noventas, pero no que su "programa" no era suficiente para expresar la profunda insatisfacción de los sectores populares, urbanos, de clase media, pero sobre todo del amplio espectro de los mestizos. Por que de alguna manera esto habían quedado por fuera de la vieja hegemonía de alianzas y liderazgos que se "habían repartido el país". Y donde "todos" habíamos perdido una y otra vez.

Una nueva contrahegomía: ¿dónde está el hegemón?

En ese ambiente de confrontación entre ciudadanía y partidocracia, se va produciendo una serie de condiciones, de rechazo ya no pasivo, sino activo frente a lo instituido: fuerzas que no operan de manera gremial (Lenin, 1947), sino que operan en el campo de lo culturalidentitario (Portelli, 1979), diremos nosotros que operan desde el campo del reconocimiento intersubjetivo, que no solo implicaban o implica una disputa al orden instituido por lo que 
Artigo original

Hegemonia - Revista Eletrônica do Programa de Mestrado em Direitos Humanos, Cidadania e Violência/Ciência Política do Centro Universitário Unieuro

ISSN: 1809-1261

UNIEURO, Brasília, número 29, Janeiro a Junho de 2020, pp. 154-176.

representa como reconocimiento ideológico, sino lo que implicaba moral, éticamente, esa "partidocracia" como antítesis de los valores de lo nacional. Sin duda, que fue difuso definir cuáles eran eso valores de lo "nacional", pero esa sumamente

claro, que la partidocracia, se constituía como la expresión, como la encarnación de esos antivalores populares.

Su propio significante, se llenaría discursivamente por todas aquellas acciones históricas, pero sobre todo políticas de la decadencia de los grupos gobernantes, como del resultado de sus acciones. Las condiciones económicas que eran negativas para la mayoría de la población, tampoco eran el centro de las movilizaciones. Aunque se exigía mejoramiento del salario básico, ya en dolarización y con una baja inflación, la lucha por el salario era central como eje económico, junto a que haya más empleo formal para acceder a la seguridad social, pero esto no fue todo, el gran lugar del significante "ciudadano" se centraba en el "hastía" colectivo contra toda la clase política, por eso el que "se vayan todos", se convertiría en la consigna mayor en el primer lustro del siglo XXI: una lucha cultural, una lucha política centrada desde las demandas de moralización del país, de "sacar a los corruptos".

En el caso del Ecuador, no había una hegemonía política previa articulada por fuerzas revolucionarias que demarcaran el sendero de acciones de la sociedad civil, por el contrario sería, más que llamarla "sociedad civil", la "ciudadanía" la que de manera espontanea fue produciendo un efecto de colectivización de voluntades alrededor de "fundar de nuevo la patria"; cohesión discursiva que fue calando en los diferentes sectores populares y medios, urbanos y rurales de las grandes ciudades, teniendo como centro a Quito (tradicionalmente esto ha sido asî). De esta manera y a diferencia de la visión que tenía Lenin, la visión y definición de Gramsci, de alguna manera logra explicar lo que comenzó a suceder en el Ecuador. Fue el efecto de ciudadanización de los sujetos sociales, fue un proceso, aparentemente, espontáneo, donde ciertos medios radiales sobre todo, como fue el caso de Radio La Luna (De la Torre, 2006), que lograron incidir en la articulación de un nuevo discurso de descontento, pero a la vez, un nuevo discurso que descentraba a la "partidocracia”; el efecto de "abramos los micrófonos a la ciudadanía”, implicó abrir el dique que contenía las valoraciones que el ciudadano común tenía sobre la sociedad ecuatoriana, sobre la clase política, sobre el Estado, sobre los partidos políticos, sobre las instituciones, sobre lo que ha sido el Ecuador y lo que debería ser. 
Artigo original

Hegemonia - Revista Eletrônica do Programa de Mestrado em Direitos Humanos, Cidadania e Violência/Ciência Política do Centro Universitário Unieuro

ISSN: 1809-1261

UNIEURO, Brasília, número 29, Janeiro a Junho de 2020, pp. 154-176.

Fue en ese campo de lo ciudadano, donde se dio la disputa, la lucha contra el grupo hegemónico, el cual no era explícitamente identificado, más allá, de cinco a lo sumo diez personas; el efecto fue mucho más efectivo: "que se vayan todos" implicaba una radicalización total, no dejar espacio, ni posibilidad de que "algún corrupto" se pueda encubrir y continuar en el nuevo momento de la política como de lo político de ese Ecuador que se quería que "renazca". "Refundar la Patria", nótese que gradualmente el concepto "patria" se dejó de escribir con minúscula, pasando a hacérselo con mayúscula, con lo cual connotaba, que la Patria, ya no podía ser la patria de todos aquellos que le habían saqueado, sino que se tenía que recuperar la "Patria" de todos.

Este cambio semántico no fue menor, significaba que en el orden lingüístico se estaba produciendo modificaciones insospechadas. El cuestionamiento ciudadano, fue total y cerrado, no había ninguna forma de negociar con los "traidores". La ciudadanía confrontada abiertamente contra la sociedad política. Como afirman Bobbio y Matteucci (2008), siguiendo a Gramsci, es desde la "sociedad civil", que para el caso ecuatoriano diremos la "ciudadanía" desde la cual se va produciendo un nuevo liderazgo político, intelectual y moral, que configura la propia "voluntad política", sin mediaciones, un reconocimiento directo, no mediado por las mediaciones tradicionales, que no eran solo los partidos políticos, sino los propios medios de comunicación privados, que iría a conformar la "voluntad de los nacionalpopular".

Esta contrahegemonía se fue tejiendo frente como un "populismo" nacional-popular, más que como una lucha de clases (Laclau, 2005), pero donde el concepto de pueblo no fue un articulador político, y no es problema de cambio de términos, para el caso ecuatoriano, la "ciudadanía" es un equivalente semántico al de pueblo, porque este por sí mismo fue agotado en el referencialidad de las élites frente a un tercero que fue excluido de manera permanente. Más de un debate superficial de conceptos, cabe poner en relieve que las significaciones operacionales, materiales, redistributivas, de reconocimiento se abarcaron alrededor del concepto de "ciudadanía" este fue el significante vacío que se llenaría a sí mismo desde una lógica, no solo de oposición, de negación a los existente, sino que se llenaría a sí mismo como el nuevo lugar de la hegemonía, no del lugar del privilegio para la acción el combate político, de un grupo, de una clase, sobre otra, sino como el lugar de la cohesión social de una diversidad de fuerzas políticas, tanto de clases sociales, como de fuerzas sociales étnicas. 
Artigo original

Hegemonia - Revista Eletrônica do Programa de Mestrado em Direitos Humanos, Cidadania e Violência/Ciência Política do Centro Universitário Unieuro

ISSN: 1809-1261

UNIEURO, Brasília, número 29, Janeiro a Junho de 2020, pp. 154-176.

Un lugar común, un nuevo sentido común de lo político, contra la política de la tradición. Este nuevo lugar del común, implico el redescubrir la política desde los lugares de lo popular, desde los lugares de sentido del común. Por lo tanto, el conflicto y la disputa no era un privilegio ni de la derecha ni de la izquierda tradicional, sino de un común que se identifica con la necesidad de "recuperar la Patria".

Para 2006 este emerge un equivalente universal, "Volver a tener Patria", se convertiría en el significante fundacional de tener un "nuevo País" (así con mayúscula). Palabra que se sentarían las bases para constituir una fuerza política por fuera del circuito: se funda el Movimiento PAIS, "Patria Altiva i Soberana" (nótese la “ $i$ ”), desde ese hecho de enunciación se construirá un discurso de un nuevo reconocimiento legítimo desde los propios actores, significando que terminar con la "partidocracia", no era la meta, como tampoco terminar con el Estado, sino que su fin era el medio para alcanzar el poder del Estado, desde un estado de situación de ruptura total con lo establecido.

Fundar el "Nuevo PAIS" pasaba porque el Movimiento Alianza PAIS (MPAIS, Alianza PAIS, etc.) se convierta en el equivalente del común, de la nueva hegemonía contra la sociedad política establecida. Por primera vez el objetivo es la "toma del poder", pero a diferencia de la vieja izquierda, esta tenía que ser a través de las reglas instituidas por la partidocracia; es decir, derrotarla en sus propias reglas de juego y significación e inmediatamente llamar a una Asamblea Nacional Constituyente. Aceptar las reglas de juego, permitía que Alianza PAIS, no sea acusada de insurgencia y de atentar a la democracia y al orden instituido del país, sino que la voluntad popular, libremente expresada en las urnas, sería que la dirima al sujeto político, como la salida a la "refundación de la Patria". Lo que Rafael Correa, discursivamente establecería como meta, salir de "la larga noche neoliberal" que había sumido a las grandes mayorías a la pobreza, a la migración forzada, a la propia dolarización donde las deudas en sucres (moneda nacional que desapareció) de los grandes empresarios se licuaron a costa de elevar los precios de los productos a niveles internacionales.

Nuevos significantes contra hegemónicos aparecieron discursivamente: "La Patria vuelve" que más allá de eslogan de campaña, daban cuenta de que la centralidad de la equivalencia se centraba en el "nuevo PAIS" y que su organización Alianza PAIS, se convertía en el epicentro de la disputa contrahegemónica. 
Artigo original

Hegemonia - Revista Eletrônica do Programa de Mestrado em Direitos Humanos, Cidadania e Violência/Ciência Política do Centro Universitário Unieuro

ISSN: 1809-1261

UNIEURO, Brasília, número 29, Janeiro a Junho de 2020, pp. 154-176.

Este movimiento de fuerzas, ya no respondía a la lógica del reconocimiento estatal o de la democracia "representativa", sino que se recorría el sendero de nuevas significaciones poniendo al límite a la Constitución de 1999, pero a la vez desconociéndola y reivindicando que el poder constituido, siendo inalienable al pueblo, tenía que ser, nuevamente, invocado por el poder ciudadano, el sujeto histórico-ciudadano, sin embargo, esto tenía que pasar por los mecanismos instituidos, la propia lógica del Estado neoliberal realmente existente.

El otro significante que contenía la emergencia de la ciudadanía fue el "Ya basta", representando el cansancio y hastío de la ciudadanía, que aparecía como un abstracto general de la voluntad general, pero que tenía que tomar forma en una nueva hegemonía. Para esto el proceso electoral de 2006, se forjó en el marco de un cerco mediático a las llamadas fuerzas de izquierda, de una nueva izquierda: indígenas, ciudadanos comunes.

Los grandes emporios mediáticos y empresariales, se presentaron en la contienda electoral del 2006. Todas las fuerzas políticas del circuito de la "partidocracia" se presentaron, tanto de la izquierda tradicional, como de las derechas del todo el arco político ecuatoriano. Es decir que, a pesar de la caída de una serie de presidentes durante una década, las mismas fuerzas política se presentaban como "alternativas", nuevas alternativas al propio pasado que habían producido. Alianza PAIS, no aparecía como favorito para estas elecciones, sin embargo, el domingo 15 de octubre del 2006, el candidato de Alianza PAIS, pasó a la segunda vuelta electoral. En primer lugar quedó Alvaro Noboa, la máxima expresión del empresariado costeño-oligárquico. Pero en la segunda vuelta y superando los contraataques discursivos de que se quería imponer un "comunismo a la cubana", las fuerzas de Alianza PAIS, de Rafael Correa, ganaron con un 56, 67\% porciento de los votos validos. Siendo significativo que el alto porcentaje de participación. En la primera vuelta llegó al 83,49\% y en la segunda vuelta subió al 89,20\% (Recalde, 2006) Lo que desechaba la tesis de que el elector no quería saber de política, que la gran mayoría era independiente o que se votaría por cualquier candidato.

Descentrar el Estado y la política: un nuevo centro político

La tesis del "asedios a lo imposible" (Acosta, Falconi, 2005), de poner fin al neoliberalismo, de soltar las fuerzas ciudadanas, de convocar a una Asamblea Nacional Constituyente, se convirtieron en los ejes del programa de gobierno (CITA), y el segundo 
Artigo original

Hegemonia - Revista Eletrônica do Programa de Mestrado em Direitos Humanos, Cidadania e Violência/Ciência Política do Centro Universitário Unieuro

ISSN: 1809-1261

UNIEURO, Brasília, número 29, Janeiro a Junho de 2020, pp. 154-176.

decreto firmado el Correa, fue la convocatoria a una Constituyente, la cual pasaría por una consulta popular y al final de ese proceso, por un Referendum aprobatorio.

Todos estos hechos políticos eran inéditos para la política ecuatoriana. Otro eje discursivo que se impuso fue "Pasión por la Patria", lo que provocaba un corte con todo lo anterior. El nuevo hegemón giraba alrededor de la vocación histórica, de la entrega total al poder ciudadano, donde la toma del poder político del Estado, era un medio, no un fin para terminar con la partidocracia y con las políticas neoliberales.

Descentrar al Estado desde una nueva Carta Magna, que lo sitúe no como el dispositivo de poder de las élites, sino de servicio "a los ciudadanos y no al mercado", donde "el ser humano por encima del capital", se convirtieron en los ejes de la "pasión" ciudadana, para salir democráticamente de un Estado neoliberal a un Estado con fin social. Esa salida debía ser el ejercicio de una democracia radical, directa, por sobre la vieja "democracia representativa" centrada en la partidocracia y sus aliados políticos, sobre todo que rápidamente se convertiría en el nuevo gran actor político, los medios de comunicación privados, podemos decir, en perspectiva que se convirtieron en efectivos partidos mediáticos, porque los tradicionales, no pudieron responder a la dinámica, a la velocidad de las transformaciones de lo que después se conocería como "revolución alfarista", "socialismo del siglo XXI", "izquierda progresista", o la denominación de una ciencia política incipiente que rápidamente la calificó como "populismo". En el sinnúmero de campos de disputa uno de altísima relevancia, fue respecto a la política exterior del Ecuador. La cual históricamente giraba alrededor de lo que los Estados Unidos definía como prioridades regionales. La idea de la integración, para nada nueva, siempre estuvo presente como integración regional, sobre todo en el modelo de integración de la Comunidad Andina de Naciones (CAN) que, para ese año, 2006, se encontraba ya en una profunda crisis de la cual no ha salido al día de hoy.

Frente a ese modelo de integración se buscaba en el proyecto de la Revolución Ciudadana otro modelo de hacer, gestionar la política exterior del país, de pensar las relaciones internacionales, de reflexionar el rol del Ecuador en el contexto andino, regionalsudamericano y global. 
Artigo original

Hegemonia - Revista Eletrônica do Programa de Mestrado em Direitos Humanos, Cidadania e Violência/Ciência Política do Centro Universitário Unieuro

ISSN: 1809-1261

UNIEURO, Brasília, número 29, Janeiro a Junho de 2020, pp. 154-176.

Hegemonía y contrahegemonía internacional: política exterior, integración latinoamericana cooperación SUR

El Plan de Gobierno de Alianza PAIS 2007-2011 (PG), presentado el 12 de mayo de 2006:

"Por que otro país posible", se establecían cinco revoluciones:

1. Revolución constitucional y democrática

2. Revolución ética: combate frontal a la corrupción

3. Revolución económica y productiva

4. Revolución educativa y de salud

5. Revolución por la dignidad, la soberanía y la integración latinoamericana.

Esta quinta revolución, implicaba ideológica y políticamente que una superación del Consenso de Washington, y todas las formas de reproducción de un modelo de desarrollo centrado en profundizar el subdesarrollo de las mayorías. Emprender una nueva visión del desarrollo, donde el mercado "sirva al ciudadano", con un Estado interventor para regular a las fuerzas y actores del mercado, requería que las acciones del Estado respecto a otros Estados tuvieran que ser modificadas. "Una nueva forma de inserción internacional" donde el aparato productivo y el mercado interno se fortalezcan.

Que la política exterior del Ecuador, se nuclee alrededor de "la defensa de la dignidad de nuestra nación y su soberanía tan amenazados por los chantajes imperiales y la sumisión de nuestros mandatarios, que nos han involucrado en conflictos y agendas ajenas" (PG, 40). Esto implicaba, no solo un cambio constitucional, que vendría con la Constitución del 2008, sino que exigía un giro radical en la práctica, pero, sobre todo, en la doctrina de las relaciones internacionales.

Se planteaba que el Ecuador debía rescatar su "dignidad y soberanía” como país. Esto implicaba fuerte conflictos con toda una tradición de práctica de la diplomacia ecuatoriana, formada, fuertemente para responder a los intereses de los Estados Unidos o de Europa. Donde el lugar común de pensar América Latina, pasaba por reivindicar el bolivarianismo desde la izquierda tradicional, que soñaba en la imitación del proceso de integración europeo. En el Plan de Gobierno, se dejaba claro que las viejas prácticas de la política exterior tenían que ser superadas, para enfrentar los nuevos desafíos internacionales en campos como el del medio ambientes: "El Ecuador, dada su riqueza cultural y genética, tiene que cumplir un 
Artigo original

Hegemonia - Revista Eletrônica do Programa de Mestrado em Direitos Humanos, Cidadania e Violência/Ciência Política do Centro Universitário Unieuro

ISSN: 1809-1261

UNIEURO, Brasília, número 29, Janeiro a Junho de 2020, pp. 154-176.

liderazgo internacional para que se cumpla y se apliquen los tratados internacionales que el país es signatario". Acuerdos, tratados, Convenios como el de Kyoto para la reducción de emisiones contaminantes. Se pone énfasis en que el Ecuador no firmaría ningún Tratado de Libre Comercio ya que atentaban contra toda forma de desarrollo endógeno que busque la reducción de la pobreza, la redistribución de la riqueza acumulada.

Desde un inicio esto implicaba una confrontación, una posición contra hegemónica, localnacional, nacional-regional-continental. Por eso el desarrollo de una "estrategia preferiblemente alienada con el resto de Sudamérica para lograr mayor poder de negociación con equidad" (PG, 41). Entendiéndose que en el contexto regional la emergencia de gobierno "progresistas" fortalecían las condiciones para enfrentar acuerdos, tratados, renegociar con las empresas petroleras extranjeras. En este punto, la propuesta de una estrategia de renegociación de los contratos petroleras se convertiría en punto de alta tensión, como fue el caso de ir por la caducidad con la petrolera OXY.

La idea de la soberanía territorial y la seguridad en el Ecuador tomó otro rumbo. Lo que se concebía como iniciativas morales, éticas, se convertían en acciones y políticas públicas instituidas democráticamente. Otro eje altamente significativo fue la intención (que de hecho se cumplió) de notificar "a los Estados Unidos la no renovación del Acuerdo sobre la Base de Manta" (Vásquez, 2019). Esto fue un epicentro de conflictos en el marco del Plan Colombia. Poner fin a la Base de Manta fue el mayor hito político en la política exterior que marcaba un antes y un después en las relaciones con los Estados Unidos. Y daba pie a impulsar procesos de integración como la UNASUR, de la cual Quito sería su capital. E impulsar la constitución de la CELAC, como centro de discusión por sobre la OEA, es decir, foros internacionales regionales para impulsar el multilaterialismo, como campo de disputa y unificación de políticas propias, en contraposición a las visiones tradicionales de afinamiento de los intereses nacionales a los continentales que ha impulsado los Estados Unidos.

Ese descentramiento, significaba, terminar con los viejos idearios de la unidad latinoamericana, sostenidos en conformar exclusivamente grandes mercados, millones de consumidores, dejando de lado la construcción de la "Gran Nación Latinoamericana" (PG, 42). Pero ese nuevo ideario pasaba por propuestas propias para el financiamiento y el desarrollo de la región, por ejemplo, la creación del "Fondo Latinoamericano para las 
Artigo original

Hegemonia - Revista Eletrônica do Programa de Mestrado em Direitos Humanos, Cidadania e Violência/Ciência Política do Centro Universitário Unieuro

ISSN: 1809-1261

UNIEURO, Brasília, número 29, Janeiro a Junho de 2020, pp. 154-176.

Finanzas y el Desarrollo, así como la constitución de empresas latinoamericanas en petróleo, electricidad, gas y telecomunicaciones" (PG, 42).

El multilateralismo se convertiría en el pilar clave para la negociación y participación del país en el escenario global. Desmitificar la globalización como el gran objetivo de integración mundial neoliberal; reivindicar la integración reconociendo las asimetrías sociales, el rol de las grandes potencias, de los países llamados desarrollados, en las causas del atraso de aquellos llamados subdesarrollados.

Abrir canales de diálogo con las potencias emergentes como fue el caso de los BRICS, sobre todo con China como una gran fuente de financiamiento, más aún, en contextos donde la deuda externa del Ecuador, sería sometida a una auditoria para declara parte de esta como ilegítima e incluso ilegal, lo que le significaría una disminución substancial de la misma para el país.

Pero hay que dejar por sentado, que el análisis aquí propuesto gira alrededor de los tiempos previos a que la Revolución Ciudadana asuma el poder e inicie una década de transformaciones para el Ecuador.

$Y$ es relevante, reafirmar este punto ya que existe un lugar común en señalar que el gobierno inicio su gestión sin un plan de gobierno o que la ciudadanía no lo conocía. Sin embargo, no se ha hecho una exploración de los momentos de conformación de un bloque contra hegemónico y posteriormente hegemónico, sin el cual no es posible comprender las lógicas de la nueva dominación y del campo de lo ciudadano-popular.

Este campo de disputa de las relaciones internacionales ya no se centraba en un mundo paralelo a la política nacional, por el contrario, se establecen que las relaciones internacionales deben tener una prioridad desde las relaciones regionales y la seguridad interna para enfrentar los problemas derivados de los conflictos armados en Colombia o las nuevas amenazas regionales como el narcotráfico.

Lo que exigía pensar desde una nueva "geopolítica donde lo regional, lo regional, lo nacional, y lo local están vinculados a la satisfacción de necesidades ambientales y culturales" (PND, 2007). Este giro a la izquierda, implicó fuertes confrontaciones no solo con los grupos de poder tradicional, sino con las propias fuerzas de las izquierda tradicional, que se oponían a un programa de este tipo si no se las incorporaba como actores centrales.

Esta disputa rompió cualquier opción de conformar un bloque de poder más amplio, peor aún cuando en cada proceso electoral el Movimiento PAIS, el Gobierno, ganaban una y otra 
Artigo original

Hegemonia - Revista Eletrônica do Programa de Mestrado em Direitos Humanos, Cidadania e Violência/Ciência Política do Centro Universitário Unieuro

ISSN: 1809-1261

UNIEURO, Brasília, número 29, Janeiro a Junho de 2020, pp. 154-176.

vez (hasta el 2017 serían 15 victorias sucesivas). Esto implico un nuevo campo de tensiones, una bloque contrahegemónico desde la oposición (derechas e izquierdas tradicionales) a las cuales se sumaron los grupos de oposición regional.

Pero a medida que las confrontaciones se sucedían, se emprendió una fuerte movilización por la integración en distintos frentes: ALBA; UNASUR; CAN; MERCOSUR; CELAC.

Sin duda, que el discurso de la integración regional, del multilateralismo llevó al Ecuador a nuevos escenarios e internamente, se genero una opinión pública de que ese nuevo rol o protagonismo del país era positivo, la idea de que el "país tenía algo que decir al mundo", fue tomando cuerpo y que la misma diplomacia tenía que ser democratizada, que sus cuerpos estamentales tenían que ser abiertos y expresar la diversidad del país.

Esto trajo, posteriormente, en una renovación de funcionarios de carrera, donde por primera vez, miembros de los grupos históricamente excluidos: indígenas, afros, montubios, incluso mestizos, se incorporaron a la carrera diplomática. Quizás este ha sido uno de las transformaciones culturales más dramáticas que ha vivido la estructura diplomática, la cual históricamente fue constituida, producida y reproducida desde los grupos blanco-mestizos elitistas.

Los sucesivos apoyos electorales fueron afianzando esta lógica de la nueva dominación de lo nacional-popular (Freidenberg, 2009; Arévalo, 2014) . Una reconfiguración de las relaciones de poder, de los escenarios de disputa y las particulares formas de la reproducción hegemónica de la Revolución Ciudadana, que como hemos observado surgió de las movilizaciones ciudadanas de los sectores populares, de la clase media afectada por la dolarización, por los procesos de migración masiva, como por el desgaste

por la perdida de consenso que la partidocracia logró en la ciudadanía. Y que sentaron las bases para una década de gobierno de la Revolución Ciudadana en el Ecuador.

Finalmente, cabe recalcar que este análisis se ha centrado en los tiempos previos de la configuración hegemónica, con el objetivo de comprender los escenarios que llevaron al triunfo de Rafael Correa, la configuración de un nuevo tipo de "pacto social" para un ejercicio de poder desde eso llamado "Patria", que aún faltan muchos análisis de lo que ocurrió en cada sector de la sociedad durante esta década, pero también se evidencia la falta de análisis de las condiciones que permitieron la gestación de un proceso social, económico y político que se ve en ciernes en estos momentos en el Ecuador. 
Artigo original

Hegemonia - Revista Eletrônica do Programa de Mestrado em Direitos Humanos, Cidadania e Violência/Ciência Política do Centro Universitário Unieuro

ISSN: 1809-1261

UNIEURO, Brasília, número 29, Janeiro a Junho de 2020, pp. 154-176.

\section{Conclusiones}

El presente artículo ha evidenciado las construcciones discursivas contra hegemónicas, hegemónicas del proyecto político de la Revolución Ciudadana en sus momentos previos a la toma del poder. Esa configuración de nuevos actores, nuevos escenarios, bajo la generación de un discurso de recuperación de la "Patria para todos", de romper el sistema anterior de partidos políticos, calificado como "partidocracia", permitió la configuración de un nueva hegemonía, desde narrativas de los ciudadano, del Estado como herramienta al servicios de las mayorías, para producir redistribución de la riqueza y que para el campo internacional, para las relaciones internacionales, para la política exterior significó con gran claridad una toma de posición respecto a los Estados Unidos, como de los aliados regionales en el llamado "giro a la izquierda".

Este en un primer intento en un grupo de investigaciones sobre los momentos previos, estructurales-coyunturales en la generación de nuevos actores y discursos que en los años posteriores se materializarían en un proceso hegemónico nunca antes visto en el Ecuador.

La producción de discursos, enunciados, de nuevos significantes, de articuladores de sentido, de "ideas movilizadoras" fueron nucleadas alrededor de la figura del presidente Rafael Correa. Discursos que ahora están siendo procesados desde el análisis del discurso crítico para comprender cuál fue el rol, la dimensión y alcance de los mismos en la configuración de un nuevo orden y poder hegemónico en el Ecuador durante la década que va desde el 2007 al 2017.

\section{Referencias}

Acosta, A. (2001). Breve historia económica del Ecuador. Corporación Editora Nacional, Quito. Retrieved from: http://www.discursos.org/oldarticles/El $\% 20 \mathrm{an} \%$ E1lisis $\% 20 \mathrm{cr} \%$ EDtico $\% 20 \mathrm{del} \%$ 20discurso.pdf

Acosta, A., Falconí, F. (ed), (2005). Asedios a lo imposible. Propuestas económicas en construcción. FLACSO, Ecuador. ILDIS. Quito, Ecuador. Retrieved from: https://biblio.flacsoandes.edu.ec/libros/digital/43325.pdf 
Artigo original

Hegemonia - Revista Eletrônica do Programa de Mestrado em Direitos Humanos, Cidadania e Violência/Ciência Política do Centro Universitário Unieuro

ISSN: 1809-1261

UNIEURO, Brasília, número 29, Janeiro a Junho de 2020, pp. 154-176.

Alianza PAIS, (2006). Plan de Gobierno del Movimiento PAIS 2007-2011. Un primer gran paso para la transformación radical del Ecuador. Retrieved from: http://www.latinreporters.com/equateurRafaelCorreaPlandeGobiernoAlianzaPAIS. pdf

Arévalo, G. (2014). Ecuador: economía y política de la revolución ciudadana, evaluación preliminar. CENES. Volumen 33 - N. 58. Julio-diciembre. Págs 109-134.

Ayala Mora, E. (2008). Resumen de Historia del Ecuador, Corporación Editora Nacional, Quito.

Retrieved

from: http://repositorio.uasb.edu.ec/bitstream/10644/836/1/AYALAE-CON0001RESUMEN.pdf

Becker, M. (2006). Comunistas, indeginistas e indígenas en la formación de la Federación Ecuatoriana de indios y el Instituto Indigenista Ecuatoriano. Iconos. Revista de Ciencias Sociales. Núm. 27, Quito, enero 2007, pp. 135-144. Retrieved from: http://www.flacso.org.ec/docs/i27becker.pdf

Bobbio, N. (2008). Diccionario de política. México, D.F.: Siglo XXI Editores.

Buriano A. (2014). El "espíritu nacional” del Ecuador católico: política y religión. Procesos. Revista Ecuatoriana de Historia n. 40, (julio-diciembre).

Dalle, P., Bonilio, P., Sautu, R., Elbert, R. (2005). Manual de metodología. Construcción del marco teórico, formulación de los objetivos y elección de la metodología, CLACSO, Campus Virtual. Retrieved from: http://biblioteca.clacso.edu.ar/gsdl/collect/clacso/index/assoc/D1532.dir/sautu2.p df

De la Torre, C. (2006). Protesta y democracia en Ecuador: la caída de Lucio Gutiérrez en Europa América Latina. Fundación Konrad Adenauer, N 21. Retrieved from: http://biblioteca.clacso.edu.ar/ar/libros/grupos/lopezma/12torre.pdf

Freidenberg, F. (2009). La Revolución Ciudadana, viejas práctica políticas y el nuevo sistema de partidos ecuatoriano: cuando lo que se institucionaloiza es el sentimiento antipartidista. Instituto de Iberoamérica. Universidad de Salamanca. Retrieved from: http://americo.usal.es/oir/opal/textos/Flavia_Freidenberg.pdf

Gramsci, A. (1984). El materialismo histórico y la filosofía de Benedetto Croce. Buenos Aires: Nueva Visión. 
Artigo original

Hegemonia - Revista Eletrônica do Programa de Mestrado em Direitos Humanos, Cidadania e Violência/Ciência Política do Centro Universitário Unieuro

ISSN: 1809-1261

UNIEURO, Brasília, número 29, Janeiro a Junho de 2020, pp. 154-176.

Gramsci, A. (1999). Cuadernos de la cárcel. México, D.F.: Era: Benemérita Universidad Autónoma de Puebla.

Honneth, A. (1997). La lucha por el reconocimiento. Por una gramática moral de los conflictos sociales. Barcelona: Crítica.

Honneth, A. (2006). El reconocimiento como ideología. ISEGORÍA, N 35. Julio-diciembre, $129-150$.

Retrieved

from: http://isegoria.revistas.csic.es/index.php/isegoria/article/view/33/33

Honneth, A. (2010). Crítica del agravio moral. Patologías de la sociedad contemporánea. FCE, Argentina.

Informe Latinobarómetro 2017. Banco de datos en línea. Corporación Latinobarómetro. Retrieved from:

https://dialnet.unirioja.es/descarga/articulo/6068196.pdf

Larrea. C. (s/f). Crisis, dolarización y pobreza en el Ecuador. Retos para la integración social de los pobres en América Latina. Retrieved from: http://biblioteca.clacso.edu.ar/ar/libros/grupos/barba/13larrea.pdf

Laclau, E. (1978). Política e ideología en la teoría marxista: capitalismo, fascismo, populismo. Madrid: Siglo XXI editores.

Laclau, E. (1987). Hegemonía y estrategia socialista. Hacia una radicalización de la democracia. Siglo XXI, Madrid.

Laclau, E. (2005). La razón populista. Buenos Aires: Fondo de Cultura Económica de Argentina.

Lenin, V.I. (1947). Dos tácticas de la socialdemocracia en la Revolución democrática. Moscú: Ediciones en lenguas extranjeras.

Luxemburgo, R. (1975). Huelga de masas, partido y sindicatos. Buenos Aires: Siglo XXI Editores,

McCombs, M. (2004). Estableciendo la agenda: el impacto de los medios en la opinión pública y en el conocimiento. Barcelona: Ediciones Paidós Ibérica.

Muñoz, P. (2006). Ecuador: reforma del Estado y crisis política, 1992-2005. HAOL, Núm, 11 (otoño), 101-110. Retrieved from: https://dialnet.unirioja.es/descarga/articulo/2380208.pdf 
Artigo original

Hegemonia - Revista Eletrônica do Programa de Mestrado em Direitos Humanos, Cidadania e Violência/Ciência Política do Centro Universitário Unieuro

ISSN: 1809-1261

UNIEURO, Brasília, número 29, Janeiro a Junho de 2020, pp. 154-176.

Oleas, J. (2017). Ecuador 1980-1990: crisis, ajuste y cambio de régimen de desarrollo. Am. Lat. Hist. Econ., año 24, núm. 1, enero-abril. Retrieved from: http://www.scielo.org.mx/pdf/alhe/v24n1/2007-3496-alhe-24-01-00210.pdf

Paltán, J. (2005). La crisis del sistema político ecuatoriano y la caída de Gutiérrez. Iconos. Revista de Ciencias Sociales. Núm, 23, Quito, septiembre, pp. 45-52. Retrieved from: https://www.redalyc.org/html/509/50902306/

Paz y Miño, J. (2013). La Revolución Juliana en el Ecuador (1925-1931). Serie Historia de la Política Económica del Ecuador. Quito: Ministerio Coordinador de Política Económica. Quito, Ecuador.

Plan Nacional de Desarrollo 2007-2010. Planificación para la Revolución Ciudadana. Retrieved from: http://www.planificacion.gob.ec/wpcontent/uploads/downloads/2013/09/Plan-Nacional-Desarrollo-2007-2010.pdf

Portelli, H. (1979). Gramsci y el bloque histórico. Buenos Aires: Siglo XXI.

Ramírez, J., Ramírez, F. (2005). La estampida migratoria ecuatoriana. Crisis, redes transnacionales y repertorios de acción migratoria. CIUDAD. Centro de Investigaciones. Retrieved from: http://biblioteca.clacso.edu.ar/Ecuador/ciudad/20121009105948/ramirez.pdf

Ranciere, J. (2006). Política, policía, democracia. Santiago de Chile: LOM Edicionaes.

Recalde, P. (2006). Elecciones presidenciales 2006: una aproximación a los actores del proceso. Iconos. Revista de Ciencias Sociales, Núm. 27, Quito, enero, 2007, pp. 15-25. Retrieved from: http://www.flacso.org.ec/docs/i27recalde.pdf

Rodas, G. (2000). La izquierda ecuatoriana en el siglo 20. Aproximación histórica. Abya Yala. Quito, Ecuador. Retrieved from: https:// digitalrepository.unm.edu/cgi/viewcontent.cgi?referer=https://www.google. $\mathrm{com} /$ \&httpsredir $=1 \&$ article $=1092 \&$ context $=$ abya_yala

Saltos, N. (2017). Genealogía y modernización de las fuerzas armadas en el Ecuador. Ciencia Política. Vol. 12, N. 24 agosto. Retrieved from:

https://dialnet.unirioja.es/descarga/articulo/6068196.pdf

Tomalá, M.A. (2016). El proceso migratorio en el Ecuador despúes de la crisis económicafinanciera de 1998-1999. Un análisis histórico descriptivo. Retrieved from: https://old.reunionesdeestudiosregionales.org/Santiago2016/htdocs/pdf/p1696.pdf 
Artigo original

Hegemonia - Revista Eletrônica do Programa de Mestrado em Direitos Humanos, Cidadania e Violência/Ciência Política do Centro Universitário Unieuro

ISSN: $1809-1261$

UNIEURO, Brasília, número 29, Janeiro a Junho de 2020, pp. 154-176.

Valero, P. (2015). Un Proyecto de modernidad católico: el Ecuador de García Moreno. De Raíz Diversa, vol. 12, núm., 2, octubre-diciembre, pp. 155-182. Retrieved from: http://latinoamericanos.posgrado.unam.mx/publicaciones/deraizdiversa/no.2/Vale ro.pdf

Van Dijk, T. (1999). El análisis crítico del discurso. Anthropos (Barcelona), 186, septiembreoctubre, 23-36. Pp. Retrieved from: http://www.discursos.org/oldarticles/El\%20an $\%$ E1lisis $\% 20 \mathrm{cr} \%$ EDtico $\% 20 \mathrm{del} \% 20$ discurso.pdf

Vásquez, W. Implicaciones políticas y geopolíticas del desmantelamiento de la Base Militar estadounidense de Manta en 2009. Academia Nacional de Historia del Ecuador, en imprenta. Quito, Ecuador. 